\title{
Lessing: la muerte desde el panteísmo helenista
}

\author{
(Lessing: Death in \\ Hellenistic pantheism)
}

\author{
Iván FERNÁNDEZ FRÍAS
}

Recibido: 17 de julio de 2011

Aceptado: 6 de enero de 2012

\section{Resumen}

Partiendo de la crítica a la metafísica dualista entre vida/otra vida propia del cristianismo desde Pablo de Tarso, el presente artículo pretende demostrar cómo Lessing reexamina la concepción de la muerte siguiendo la tradición del panteísmo helenista (Bruno, Spinoza, Leibniz...). La teoría lessingniana sobre la muerte cristaliza en una antropología de carácter optimista que permite el continuo perfeccionamiento del individuo y de la humanidad toda, evitando el sentimiento de culpa y miedo que emana desde la escatología cristiana.

Palabras clave: metafísica dualista, Lessing, muerte, panteísmo helenista, continuo perfeccionamiento.

\section{Abstract}

Through the critique of dualistic metaphysics / life / other life proper to Christianity from Paul of Tarsus, this article aims to demonstrate how Lessing revisits the concept of death in the tradition of Hellenistic pantheism (Bruno, Spinoza, Leibniz ...). Lessingniana theory about the death crystallizes in an anthropology optimistic character that allows for continuous improvement of individuals and mankind as a whole, avoiding the feeling of guilt and fear emanating from the Christian eschatology.

Keywords: dualistic metaphysics, Lessing, death, Hellenistic pantheism, continuous improvement. 


\title{
1. A modo de introducción
}

\author{
"Ein Mann wie Lessing täte uns not" \\ (Necesitamos otro Lessing) \\ J.W.Goethe
}

Gotthold Ephraim Lessing (1729-1781) fue probablemente el poeta más importante de la ilustración alemana. Igual que Kant, contemporáneo suyo, elaboró todo un aparataje crítico como parte de su actividad intelectual; pero se trataba de una tarea que iba en dirección opuesta a la crítica kantiana. Lessing dirigirá su mirada a los aspectos externos de la cultura: el arte, la literatura, el teatro... son algunos de los temas que más le interesan y que más tiempo ha dedicado a su estudio. Estos temas, en continua evolución, sugieren una de las características más importantes de Lessing: la imposibilidad fáctica de decir la última palabra. En este sentido, en este estado de continua apertura del pensamiento de Lessing, se puede afirmar, sin equivocarse, que la crítica que el sajón realiza es mucho más genuinamente moderna que la del filósofo de Königsberg.

Bajo la atenta mirada de ese pensamiento que nunca agota su sentido, prefigurando ya lo que daría de sí la hermenéutica dentro de la filosofía, Lessing intenta establecer las reglas del gusto para su época. Sin embargo, lejos de fijar estas reglas con un discurso apriorístico, realizará bajo inducción una tarea que se sabe provisional, único camino científico que le parece correcto. En este sentido, el enfrentamiento puede entenderse bajo las siguientes características:

1. Francia era por aquel entonces la cultura dominante en lo referente al gusto, a la literatura, al teatro. La nueva corriente alemana se define contra esta cultura dominante bajo el aspecto de la crítica.

2. Los interlocutores fundamentales en esta disputa fueron Voltaire, como máximo exponente de la Ilustración francesa (eminente por sus escritos literarios, filosóficos e históricos) y el autor que nos ocupa, Lessing.

3. Partiendo desde dos ámbitos completamente distintos, que se pueden entender bajo la dialéctica de la dominación, la cultura francesa (dominante) se reafirmarán constantemente en este envite como la cultura a seguir. Mientras tanto, en Alemania va creciendo la desconfianza hacia la propia cultura, que se ha mostrado a todas luces insuficiente y, en el mejor de los casos, como un pálido reflejo del país vecino.

La necesidad de fundar una cultura alemana propia viene precedida por tres tareas que se convertirán en tópicos, y que Lessing ayuda a fijar:

1. La necesidad de crear un arte dramático no francés. 
2. La superación en filosofía del deísmo francés y la teología natural que le era propia.

3. La revisión del clasicismo en clara disputa con Winckelman.

El teatro clásico francés, personificado por Racine, es criticado por Lessing debido al enaltecimiento de esta institución artística como baluarte de moralidad. Para Lessing:

La verdadera tragedia debe producir pasiones ${ }^{1}$

Profundizando en este aspecto, Lessing se percata de la importancia de que el teatro sea fiel reflejo del Volk ${ }^{2}$ que lo genera. Es decir, que el teatro no puede quedarse simplemente en representar las más excelsas virtudes del ser humano, o de un pueblo determinado. Fiel al Volk que lo engendra, el teatro auténtico deberá ser capaz de representar tanto los vicios como las virtudes del ser humano. Un nuevo teatro para un nuevo espectador: una auténtica reforma artística de la institución teatral.

Frente a la tragedia clásica, representada en la figura de Edipo, una tragedia de reyes y de acciones heroicas, de gestas y proezas que enfrentan al héroe a un destino o fatum que se alza como inmutable, el nuevo teatro alemán aspira a revalorizar la expresión trágica en las situaciones cotidianas. Alentado por el descubrimiento de la imposibilidad real de escapar de la tragedia, el teatro aspira a mostrar como ésta aparece en cada vida privada. Este tipo de teoría teatral viene enraizada en Aristóteles, que afirmaba que el teatro debe producir una experiencia catártica.

De esta creencia en poder ver la experiencia trágica en cualquier tipo de vida, surge también una nueva categoría: el interés (como valor supremo otorgado a una vida individual); es decir, no tiene que ser ya más un héroe o un rey el personaje trágico, sino un padre, madre, hermano o un hombre/ mujer cualquiera: un hombre en general. De esta estructuración nueva de los personajes surge evidentemente una nueva categorización de la humanidad. Ahora, con la pretensión de realizar este tipo de representaciones, el valor que adquiere la humanidad cristaliza en una comunidad de realidad más fuerte que cualquier división social en clases o estamentos. De esta forma, el nuevo teatro burgués alemán cree poder representar las inquietudes de la humanidad toda en unos personajes que no pertenezcan a la nobleza, lo que permite que un mayor número de espectadores pueden sentirse identificados. Señalar el error que bajo este tipo de creencia subyace; un error que forma parte de la confusión ilustrada obnubilada por los conceptos de progreso y comunión de hombres libres: si a un hombre le despojas de su condición social, brillará en él arquetipos de la humanidad entera.

1 Villacañas (1994), p.35.

2 Volk: pueblo o nación. 
Lessing pretendía, además, dar un paso más allá en la reforma que Lutero había comenzado en el siglo XVI. Mientras éste consiguió liberar a la iglesia del yugo de la tradición, de la autoridad temporal y externa del sacerdocio encarnada por la figura del Papa, Lessing quería dar un paso más allá: la liberación del yugo de la letra muerta que suponía la Biblia. Documento único e irrepetible, el protestantismo se afanaba en interpretarlo de manera casi literal, mientras que Lessing otorgaba una relevancia especial al origen de la misma. Poniendo el acento en la tradición oral que se encontraba bajo los relatos bíblicos, Lessing afirmaba que la petrificación de los textos bíblicos venía conforme a la estandarización de la autoridad de la Iglesia primitiva.

Bajo este espíritu eminentemente Ilustrado, Lessing creía ser capaz de establecer tres tareas para con la religión que consideraba como indispensables para su época:

1. La distinción entre la religión de Cristo y la religión cristiana; que conllevaba a la reconstrucción de la tradición oral y a relacionarlo con el canon de los libros sagrados ortodoxos.

2. La defensa de un acceso estrictamente espiritual al cristianismo, sin dogmas ni sacerdotes.

3. La construcción de una verdadera filosofía de la historia en términos de evolución y despliegue de la razón mediante la sucesión de las revelaciones.

$1^{\circ}$ Lessing afirma que la religión cristiana es incluso anterior a los evangelistas y a San Pablo. Define a la religión cristiana como:

conjunto de las doctrinas de fe contenidas en los símbolos de los cuatro primeros siglos de la Iglesia cristiana. ${ }^{3}$

Esto puede reducirse a la llamada Regula Fidei; es decir, al padre nuestro original y a la fórmula bautismal. Sin embargo, la religión de Cristo es otra cosa. Se trata de la religión que Cristo, como persona, profesó en tanto que hombre. De esta manera, también se puede hablar de la religión de Buda o de la religión de Sócrates.

$2^{\circ}$ La religión cristiana se basa en es espíritu trinitario de dios; es decir, que Cristo es a la vez dios y logos. Para Lessing, el trinitarismo ha de dar paso a una religión únicamente del espíritu. ¿Cuál es la diferencia? El cristianismo otorga verdad vital a su fe, vive en ella y para ella. La objetiva. El nuevo cristianismo del espíritu debe legitimarse en la experiencia vital liberadora del cristianismo como sujeto:

Siente que es verdadero y se siente feliz en él. ${ }^{4}$

\footnotetext{
3 Villacañas (1994), p. 45.

${ }^{4}$ Ibídem., p. 47.
} 
En este nuevo cristianismo, basado en el espíritu, se han de reunir el logos y el espíritu, la razón y el corazón: la palabra y la vida interior del hombre.

$3^{\circ}$ Por último, la construcción de una verdadera filosofía de la historia surge de ese despliegue libre del cristianismo posibilitado por la reforma protestante. Igual que la razón humana, que tiene la necesidad inherente de desplegarse como parte de su propia esencia. Este tipo de pensamiento, de clara raigambre espinosista, prevé el perfeccionamiento continuo en etapas sucesivas de la razón humana, anticipadas por la imaginación. Es decir, trasladado a la historia: la revelación es el paso dominado por la imaginación para que la razón se establezca de una manera precisa y consciente.

\section{La idea de la muerte en el cristianismo: Pablo de Tarso}

La muerte oculta en sí misma todos los misterios del hombre...El cristianismo es la religión que reconoce la muerte de un hombre como el suceso más fundamental de la historia de la salvación y de la historia universal...y por tanto, no cabe admirarse de que la muerte no sea algo que ocurre en la muerte junto a muchas cosas, sino que sea aquello en lo que el hombre mismo se realiza en su condición definitiva. ${ }^{5}$

Del texto de Rahner podemos deducir varios aspectos sobre la muerte en el cristianismo. Sin aviso ni reserva, la voz "muerte" ha sido completamente estandarizada por el cristianismo según la teoría paulina, de la que proceden los rasgos culturales sobre la defunción que han perdurado y cristalizado hasta nuestros días. Tal teología limitaba geográficamente con una forma ya olvidad del cristianismo primitivo, que podemos denominar extremo-occidental o celta, con un naturalismo exacerbado y la permisión de que sus monjes se casaran. Por el otro extremo, en Oriente, limitaba con el cristianismo helenista, vinculado inexorablemente con la unidad cósmica de todas las cosas y la presencia en la Naturaleza de la divinidad en todas sus formas, incluido la naturaleza sexual (que se alza no sólo como no-pecado, sino como algo sagrado, espiritual). ¿Qué pasó con este cristianismo polimorfo?

La muerte es el centro rector de la Historia Universal. Todas las formas secularizadas de Occidente, que provienen del fondo común del cristianismo, entienden la muerte según la concepción martirial y salvadora: la muerte como destino existencial. Este tipo de creencia construye la historia (la de occidente) bajo imaginaciones sangrientas; ya sean éstas de carácter activo_cruzadas, guerras de religión, inquisición_o pasivo _ glorificación del martirio, la cruz como símbolo...

\footnotetext{
${ }^{5}$ La cita es de Rahner (Saramentum Mundi, 1973) traducida por Agustín Andreu en el estudio introductorio de Lessing (1992), p.xxxv.
} 
Muerte y cruz: son los dos vectores que configuran la disposición del cristianismo occidental. La muerte redentora y liberadora mediante la cruz salvadora. La cruz es símbolo de las más diversas manifestaciones religiosas. A pesar de su origen material, de su obviedad, la cruz se erige desde la tradición paulista como el mayor misterio de la humanidad (Mysterium Crucis). Y si embargo, las palabras cruz y crucifixión apenas aparecen en el N.T., sino es en las narraciones evangélicas de la muerte y pasión de Cristo. Solamente en escritos relacionados con Pablo de Tarso y en las cartas paulinas. La cruz es el símbolo con el que chocó Pablo para comprender a Cristo. Tuvo que comprender primero la cruz de Jesús para ver en ella la cruz de Cristo. La cruz además en su aspecto cosmológico, en ciertas gnosis, se relaciona como la misma posibilidad de creación y cosmos. Según las tradiciones maniqueístas:

Este Jesús, cósmico e intemporal, está crucificado en la Materia a la que su alma luminosa está mezclada; el mundo entero es la "Cruz de la Luz" (...) El devenir del mundo es, pues, el decurso de la Pasión de un Dios que es su propio Salvador, y la historia de la humanidad es el drama de nuestra Pasión y de nuestra Salvación, consustancialmente solidarias de ese ser y ese proceso míticos. Esto es lo que hace que el universo tenga algún sentido. ${ }^{6}$

Recopilando un poco, podemos afirmar que la visión de la muerte del cristianismo occidental viene directamente de las doctrinas de Pablo de Tarso, Agustín de Hipona y Lutero, que revivió la doctrina pasa el mundo alemán. Como afirma Dilthey:

la idea de sacrificio (o muerte sacrificial en la Cruz), que seguía pesando sobre la humanidad en formas de religiosidad periclitadas y que ocupaba otra vez un lugar central en el cristianismo paulino de Lutero. ${ }^{7}$

Contra esta muerte se enfrentará Lessing, siguiendo a Leibniz, disolviendo el dogma de la justificación por la fe que exige la división entre el Padre castigador y el Hijo suplicante o salvador de toda la humanidad mediante su muerte, y que a su vez divide "al Ser divino creador y a la naturaleza universal creada". 8

Una consecuencia más de que la tradición paulista y agustiniana de la muerte: con el pecado original del primer hombre, el pecado entró en el mundo, y con él, la muerte. No se trata sólo de que la muerte sea para el hombre por la caída desde el edén, sino que entra la muerte y la corrupción en la naturaleza misma. La dogmática eclesiástica relaciona estos dos pasajes bíblicos:

\footnotetext{
6 Puech (1957), p. 61.

7 Dilthey (1978), p. 90.

8 Ibídem., p. 91.
} 
Génesis 3, 17: “...maldito será el suelo por tu causa”.

Romanos 8, 20-22: “...la creación entera hasta ahora gime y siente dolores de parto...las criaturas están sujetas a la vanidad...serán liberadas de la servidumbre de la corrupción."

La tradición paulina inyecta el desorden del pecado original del hombre a la naturaleza entera. Ahora, la naturaleza vomita monstruos e irregularidades por la corrupción del ser humano. El cristianismo, que afirma la corrupción de la naturaleza por el pecado del hombre, tiene como fundamento la salvación de la culpa originaria. Sin embargo, la concepción de la muerte salvadora vuelve a sujetar el concepto (el de muerte) a la cúpula del edificio cristiano: sólo mediante la muerte meritoria de un sujeto divino se podrá alcanza tal salvación. Aunque se trate de una imagen de origen gnóstico, casi mistérica, el cristianismo occidental ha intentado racionalizarla hasta el extremo. Algunas de las teorías que mayor vigencia tuvieron fueron:

1. Teoría de los derechos del demonio. El demonio, al engañar a Adán, adquiere los derechos sobre la humanidad entera. Con la muerte de Jesús para salvar al hombre, al no estar sujeto éste al pecado original, el demonio pierde todos sus derechos gracias a la muerte redentora de dios.

2. También tuvo una amplia acogida la teoría de la muerte de Cristo como pago de una deuda a un Dios objetivo que había sido mancillado por la caída del hombre mediante el pecado original.

3. Teoría del segundo Adán. Cristo, segundo Adán, muere en el árbol de la cruz como expiación por el pecado del primer Adán, por su desobediencia con el árbol del conocimiento del bien y del mal.

La naturaleza queda ahora purificada por el mérito de Cristo en su muerte redentora. El mérito (la cultura del mérito) aparece en escena bajo estas creencias paulistas. Dios no puede merecer ante Dios mismo. Pero si se hace hombre, puede merecer ante Dios igual que puede ser tentado por el demonio. El misterio teándri$\mathrm{co}^{9}$ que es la muerte de Jesucristo será todo un quebradero de cabeza para las disputas teológicas, que acabarán por establecer una soteriología del mérito, que quedará proyectada en la cultura occidental en un régimen civil y moral de méritos. La vida quedará como campo del merecimiento para la salvación eterna y definitiva en un más allá post-mortem.

La caracterización de la dicha o la salvación como definitiva es un rasgo característico de la escatología cristiana. Habrá un instante que será absolutamente final. El individuo, al morir, se encontrará a sí mismo ante el cumplimiento definitivo de

9 Teándrico, adj.- relativo a la unión en Cristo de la naturaleza divina y humana. (http://ec.aciprensa.com/quees.htm). 
su destino como ser humano. Este carácter definitivo es algo, para el cristianismo, intrínseco a la misma muerte. Momento interno del mismo morir. La vida, reducida a trámite para el destino final o la muerte salvífica, queda reducida a meditatio mortis. El cristianismo intenta promover en sus fieles el pensamiento sobre la muerte cuando aún se está a tiempo de pensar en ella. Es Rahner quien expone acertadamente la tesis del cristianismo paulino, agustiniano y luterano-calvinista: el alma separada del cuerpo no pierde su relación con el Universo. Rahner se inspira en Leibniz, pero no es fiel al pensamiento del filósofo alemán cuando establece que:

el alma no es nunca mónada cerrada, sin ventanas, sino siempre en comunicación con la totalidad del mundo. 10

La mónada no es nunca modelo de cerrazón e incomunicación, sino de identidad recíproca y comunicación interior. Además, la corporeidad inherente de la mónada es de carácter metafísico, siendo indispensable una radical corporeidad organizada como reflejo y reflectora del universo entero. El problema radica en el carácter definitivo que la ortodoxia cristiana otorga a la situación de la individualidad concebida como mónada o microcosmos. Tanto para Leibniz, Lessing o para Spinoza y Giordano Bruno, cualquier carácter definitivo de esta "parte/todo del Todo/Único es contra naturam".11

\section{Sobre la concepción de la vida desde la muerte}

Dice Lessing que los discípulos de Cristo pregonaron las virtudes de la salvación eterna en "la otra vida", enseñanza revelada por Cristo a los judíos y comunicada por espíritu y fuerza ${ }^{12}$ gracias a los apóstoles a todos los hombres. Sin embargo, las consecuencias directas de tal enseñanza se transforman irremediablemente en un desprecio hacia "esta vida". Desde los primeros compases del cristianismo, la vida y la muerte terrenales son objeto de desprecio, debido a la gloria eterna que Cristo promete. La vida no tiene valor, pues sólo es un tránsito hacia la dicha eterna con Dios. La muerte carece de verdad, pues es sólo una falsa muerte que revelará la vida que se promete en el más allá.

Este tipo de creencia llevó a ciertos grupos marginales de cristianos a buscar el suicidio en todas sus formas, o a realizar supuestos actos heroicos buscando la muerte. Pues canjear esta vida sin sentido por la dicha eterna era un buen negocio.

\footnotetext{
10 La traducción de Rahner de esta cita se encuentra en Lessing (1992), p. XL; obra de Agustín Andreu en el estudio introductoria.

11 Lessing (1992), p. XLI.

12 Ibídem., en "Sobre la demostración en espíritu y fuerza”, pp. 480-487.
} 
Según Lessing, el desprecio por la vida terrena surge de un vaciamiento de sentido: la vida no es más que vida meritoria. La conciencia de la vida como tránsito conlleva valorar las acciones sólo en tanto que estén orientadas hacia la preparación de fe para con los premios invisibles del más allá: prometidos, velados, de carácter metafísico... La imposibilidad de representación detallada de términos como "gloria eterna", "cielo" y "salvación" (o por otro lado "infierno", "condenación" o "juicio final") y la extraordinaria imaginaria artística mantuvo la tensión entre culpabilidad y recompensa para que el hombre se adaptara rápidamente al trasvase entre moralidad y coacción. Pues de tal ropaje se mostraba, frente a la libertad humana, el frío yugo de vacuas promesas en un más allá extratemporal. Si antes la extrema delicadeza y fugacidad del tiempo que se vivía hacía encajonar todas las pasiones y deseos de manera avarienta, queriendo disfrutar en todos los aspectos de la multiformidad de la realidad, ahora el tiempo terrenal es transformado en un tiempo de prueba: todo lo que se hace (o se deja de hacer) viene configurado por promesas de eternidad o regalos futuros en un más allá de gloria y dicha.

Tal deformidad, afirma Lessing, afecta a la misma esencia del ser humano. Siendo el hombre esencialmente acción, queda fijado irremediablemente como efecto, siendo lo mismo que sea para la condenación eterna o para la salvación infinita. Sólo como efecto, el ser humano divide sus pretensiones en dos mundos: las acciones de aquí son causa directa (y como tal son valoradas y juzgadas; son motivo directo de hacer o no hacer tal o cual cosa) de lo que nos ocurra en la vida futura. Incluso dado la brevedad del tiempo terrenal, el ser humano:

De activo tórnase el hombre activista apresurado e impaciente por su diligencia en merecer premios eternos. 13

Está claro que si la doctrina cristiana de la inmortalidad tienen un propósito, éste no es la división en dos vidas separadas, quedando la terrena en puro estatismo o sala de espera de las dichas futuras, paralizando la esencial actividad del ser humano. Más bien el propósito sería una ampliación de la vida moral terrena, como ampliación del espacio ético hacia la eternidad, que debería repercutir en, precisamente, acciones cabalmente impulsadas por motivos más elevados. Y, así con todo, esta dualidad entre la vida/eternidad no fue la peor de las consecuencias de la doctrina cristiana.

Pues es que ahora el tránsito que supone la muerte viene inmediatamente seguido de un juicio divino y, eventualmente, una condena de carácter divino al infierno donde el pecador sufriría castigos por toda la eternidad. La utilización general y repetida de la escatología cristiana en todos los campos posibles, desde el estético al pedagógico, jurídico o político, hizo que el concepto de muerte penetrase en la

13 Del Estudio Introductorio obra de Agustín Andreu, en Lessing (1990), p. 133. 
humanidad cristiana (occidental). Ahora la muerte es consecuencia del pecado original, mácula que lleva la humanidad toda. La doctrina de la libertad y la noción de culpabilidad cambiaron inexorablemente. Cimentadas ahora bajo el miedo y el terror, el reparto de la culpabilidad en cada uno de los hombres hará que la religión vaya empantanando todos los estratos de la vida bajo un manto de misericordia y terror. Como una siniestra letanía, los sacerdotes lanzaban siempre el mismo mensaje oculto tras sus pregones: "Existe una respuesta divina a ese miedo y a esa culpa, que favorecerá la entrada en las puertas del cielo". Sin embargo, lo realmente importante, a saber, la comprensión de la vida (de esta vida, la única de la que podemos tener racionalmente noticia) no mejoraba ni avanzaba en ningún sentido, dirá Lessing con Spinoza y Leibniz.

Juicio divino y castigo eterno: estos dos vectores fueron formando una humanidad cada vez más cercenada por los conceptos de culpa y libertad. El miedo se extiende de lo individual a lo social, creando una general mentalidad donde no se entenderá las situaciones si no es señalando un culpable. El derecho penal, coextenso ahora al derecho divino, ejercerá como ley divina durante siglos, como traducción terrenal de los presupuestos metafísicos y religiosos. ¿Y la libertad? No puede ser una lacra tan agobiante como la culpabilidad. Sin embargo, para que el hombre fuera realmente culpable, y el juicio divino sea realmente justo, la libertad se alza como la condición de posibilidad de la justicia de Dios-justo. Y como Dios es justo... la libertad se presupone como evidentísima, sin tan siquiera recurrir a desarrollos de índole filosóficos. El valor del hombre, demasiado evidentemente libre y repleto de inconsciente culpabilidad, va perdiendo su fuerza, su valor. Queda reducido a pálido reflejo de lo que fue una vez antes del cristianismo.

Para poder entender a este hombre que queda fijado para la eternidad, la religión cristiana ahonda en la dialéctica interna del concepto de Dios. Dios tiene un hijo verdadero, que es Dios también. Que se hace hombre real y hermano de la humanidad. Que Dios exige infinita satisfacción por la ofensa infinita del pecado original, y que la satisfacción de Dios sólo puede ser pagada con la muerte de Dioshijo. Así, el ser humano queda aún más obnubilado por la culpabilidad (pues hasta Dios mismo tuvo que hacerse carne para morir por el hombre) y la misericordia en la justicia de Dios. La dialéctica interna, empero, tiene un desarrollo impecable. El concepto de muerte, como decíamos, ahora antesala del juicio divino, se erige como el momento más decisivo e intenso para el ser humano. El acto más complejo de la existencia es ahora la muerte, verdadero quicio entre la vida terrenal y la dicha o el castigo eterno.

Se extendió además la idea de que la muerte natural fuera también justo pago por los pecados, lo que se tradujo en un mayor miedo si cabe a la muerte. La concepción que entiende la muerte como castigo aparece reflejada en el Nuevo Testamento, es decir, que se trata de una idea conocida por luz natural o revelación 
divina. Y estéticamente se tradujo en la figura del esqueleto. Esta figura, de rasgos obviamente desapacibles, ha reinado como expresión del terror de la muerte. Ésta es producto del pecado, como dirá San Pablo:

Romanos 6, 23: "Pues el salario del pecado es la muerte; pero el don de Dios, la vida eterna en Cristo, Jesús Señor nuestro".

La conceptualización que cristaliza en la figura del esqueleto marcó invariablemente la forma de vida y el tipo de fe en el milenio que va desde el año 400 hasta el 1400. De la más poderosa estructura ideológica, la Iglesia-Institución, surge ésta apropiación de la muerte de carácter brutal y reductor. Pues si ésta surge del pecado, desde el comienzo mismo de la vida de los infantes, ésta presente la carga de culpa. El bautizo, rito que pretende salvar al infante como motivo del pecado original, realmente penetra en la conciencia del niño, que va creciendo bajo el yugo del remordimiento y la mezcla de fantasías de condenación eterna y muerte sacrificial.

Asegura Lessing que en la misma Biblia existen otro símbolos de muerte, como el Ángel de la Muerte14, pero un esqueleto representaba mucho mejor el terror hacia la muerte, como castigo por los pecados cometidos. Tal penuria espiritual, que encogía el corazón de los hombres, se convirtió en una constante cristiana. El análisis de Lessing sobre ésta figura desapacible, que ha sido símbolo de muerte durante generaciones, abarcará el ámbito plástico (en Cómo los antiguos se imaginaban la muerte) y el literario-filosófico (en Los elpísticos).

La disputa frente a la religión popular de los griegos y romanos la ganó el cristianismo. Ofreciendo seguridad en la salvación eterna frente a la muerte, se fue diluyendo poco a poco la concepción de resignación y elegancia con la que los antiguos (bien preparados por la Tragedia) esperaban el fatum o el destino, que era igual para dioses y para hombres. Una muerte tranquila para los hombres que se habían asegurado, con dicha serena y con sus virtudes en el mundo, su recuerdo entre los amigos y descendientes. Los sabios habían enseñado a esperar la muerte y el Hades con una tristeza y resignación tranquilas, como los más excelsos de los dioses.

No obstante, frente a la religión popular y la doctrina oficial, los paganos tenían una religión secreta o exotérica que les preparaba para la muerte. Repite Lessing las palabras de Sófocles ${ }^{15}$ :

$¡ \mathrm{Oh}$, tres veces felices

Los mortales que bajan al Hades

Conociendo estos misterios!

\footnotetext{
14 Apocalipsis 9, 11: "Sobre ellos tienen como rey al ángel del abismo, cuyo nombre en hebreo es Abadón, y en griego, Apolión."

15 Lessing (1992), "Sobre los elpísticos", p. 65.
} 
Pues sólo ellos vivirán allí,

Mientras que a todos los demás

No les esperan más que mal (...)

Los versos, recogidos por Plutarco en su célebre texto "Cómo hay que leer con los jóvenes a los poetas", continúan pidiendo un contrapeso frente a estas palabras de Sófocles. Este contrapeso atenuaba el miedo y el terror con el que se llenaban millones de seres humanos al no conocer los misterios. El contrapeso tenía que ser filosófico, un camino que pudiese hacer más comprensible la muerte y más llevadero el final.

Lo importante es resaltar que, al lado de la religión oficial pagana, existía una doctrina esotérica o de misterios, que ayudaban al hombre a despojarse del terror y el miedo que el fin de la vida les producía. El objetivo de esta doctrina mistérica era alcanzar un grado mayor de esperanza y serenidad frente a la muerte. Dice Lessing, con Cicerón:

No hay nada mejor que esos misterios por lo que, de una vida tosca y feroz, se nos enseña a ser humanos, y se nos calma. Las iniciaciones, como las llaman, nos dieron a conocer los verdaderos principios de la vida, y no sólo hemos aceptado con alegría un modo de vivir, sino que lo hemos aceptado también con una mejor esperanza el morir. ${ }^{16}$

Este texto de Cicerón muestra perfectamente como la religión mistérica se encontraba ampliamente aceptada en Roma cuando llegó el cristianismo a sus puertas. Una vida alegre y una muerte llena de esperanza: esos eran los objetivos de los misterios. Una nueva actitud moral era pregonada por estos filósofos del Logos, que sólo actúan por obediencia a su razón. ¿Pero dónde se sustentan estas creencias de índole filosófica?

\section{La tendencia panteísta del helenismo. El dios de Giordano Bruno}

Los conceptos ortodoxos sobre la Divinidad ya no me aprovechan; no puedo saborearlos. Hen kai pan! No se otra cosa. ${ }^{17}$

Con esta formulación tan cercana a Spinoza, Lessing retoma el planteamiento del pensar helenista y su principio fundamental que expresó Plotino de la siguiente manera:

\footnotetext{
16 Ibídem., p. 70.

17 Lessing (1990), p. 403.
} 
...el problema fundamental de la filosofía: la cuestión ya discutida por los antiguos Sabios de cómo puede salir del Uno (...) alguna multiplicidad o dualidad u otro número. ${ }^{18}$

La tendencia del pensar helenista (del filosofar en tanto que tal, previo a cualquier conceptualización), del plotinismo a un cierto tipo de panteísmo, a algún tipo de consubstancialidad entre el alma del hombre y Dios, es a lo que podemos acudir si queremos definir esta tendencia espiritual que desemboca en el spinozismo de Leibniz, y posteriormente repercute en Lessing. La visión de continuidad entre Dios y la naturaleza posibilita una general tendencia a la asociación conceptual, a la unidad en vez de a la contraposición (como el cristianismo de raíz agustiniana).

Esta tendencia a la unicidad entiende las vicisitudes del alma humana como procesos naturales: así los síntomas de decadencia como la enfermedad y la muerte, la distinción entre bien y mal, eternidad y temporalidad... se intentan asumir siempre como propios desde un nuevo orden, y nunca emitiendo juicios morales o sentencias sobre la corrupción del ser humano. Como organismo vivo, relacionado invariablemente con Dios y con cada partícula de naturaleza, la pecaminosidad se entenderá como un fallo estético o armónico, no bajo los caracteres de culpabilidad inherentes al cristianismo, y por tanto a la cultura occidental en su totalidad. Y si acaso se piensa en la pérdida de individualidad que tal concepción del universo podría conllevar, ahí está la pluralidad de la tendencia microcósmica que ha permitido la expresión cabal de la intensidad del ente individual en la integridad del Todo natural o cósmico. De hecho, comparando las formulaciones de Lutero con las de Giordano Bruno (recuperador de la tendencia panteística del helenismo), la balanza de lo individual se inclina a favor del pensador de Nápoles. Mientras el hombre, inerte, se asemeja a un receptáculo vacío de la gracia divina en las doctrinas protestantes de raigambre luterana, Giordano Bruno escribe con un único fin:

El copernicanismo ampliado en la dirección de un universo infinito y homogéneo, poblado de innumerables sistemas solares comparables al nuestro y donde la Tierra es un planeta como cualquier otro, un universo donde la vida_la generación y la corrupción_ late y se expresa por doquier en términos similares a la Tierra; un universo sin diferencias cualitativas en sus regiones tanto en lo que se refiere al infinito espacial como a su infinita duración temporal. 19

Para poder preservar la individualidad en este universo cualitativamente idéntico, Giordano Bruno se sirve de un doble proceso definible por la familia de palabras relacionadas con contractio y contrazione 20 (a saber, contraere, contrabile,

\footnotetext{
18 Lessing (1992), p. XLV.

19 Miguel A. Granada en Introducción de Bruno (1989), p. 21.

20 Ibídem., p. 20.
} 
contrabbile, contratto...). Éstas vienen a designar la contracción o concentración en un doble proceso:

1. La primera etapa está caracterizada por Bruno como un proceso ascendente de concentración de la multiplicidad hacia la unidad: por ejemplo, la elevación intelectual, o el proceso de conocimiento tendente a captar la unidad natural.

2. Al proceso inverso, dispersión o multiplicidad de la unidad en la diversidad a través de los diferentes niveles, hasta su concreción última en la serie de los individuos particulares.

Tras este doble proceso se oculta la base ontológica de Giordano Bruno sobre el universo físico: la materia es infinita y coextensa al alma inteligente y contiene todas las semillas de todas las formas (que son capaces de brotar de su seno en virtud de un principio formador que es el alma inscrita en la materia). Existe, por tanto, una convergencia real y última de alma, forma y materia en una sustancia única que es el Todo uno. Los individuos, o entes individuales, son accidentes de ésta sustancia única. Y la muerte no existe como tal ("omnia mutantur, nihil interit") sino que Bruno sustituye la perspectiva de la aniquilación por el hecho fáctico de la mutación, de la vicissitudine universal dentro de la inmutabilidad de la sustancia única, infinita. Esta concepción de la muerte repercutirá ampliamente en Lessing, como veremos.

La línea de pensamiento que hermana a Plotino con Lessing pasa por Nicolás de cusa, Giordano Bruno y Spinoza, además de su actualización con Leibniz. Se debería añadir a Juan Escoto Eriúgena y a Dionisio Areopagita21. Atribuyéndose este nombre, Dionisio sigue el escrito bíblico que dice:

Hechos, 17, 34: "Pero algunos hombres se adhirieron a él, y creyeron, entre ellos Dionisio Areopagita, una mujer llamada Damaris y algunos otros con ellos."

De esta forma, el desconocido se atribuye una autoridad de Padre Apostólico (nombre dado en Patrística a los discípulos directos de los doce apóstoles). A pesar de que su nombre está relacionado con Pablo de Tarso, su pensamiento entra en abierta contradicción con el genuinamente paulista de ruptura entre Dios y la Naturaleza. Proclamando el motivo fundamental del panteísmo helenista, y bajo esta treta intelectual, el Areopagita pone en relación tensional directamente para el futuro cristianismo las dos vertientes: la de Pablo de Tarso de dualidad y la helenista de reconciliación o continuidad entre lo divino y lo humano.

${ }^{21}$ Me refiero al llamado Pseudo Dionisio Areopagita, teólogo y místico bizantino, para diferenciarlo del primer Dionisio Areopagita, discípulo de San Pablo que llegó a ser obispo. 
Después del trabajo de Gregorio de Nisa, que enlaza a Filón con el Areopagita a través de Plotino, de Máximo Confesor y de la mística bizantina, el motivo de fondo del panteísmo helenista queda fijado para siempre en la cultura occidental. Dice Dilthey que en el humanismo Renacentista reaparece:

el teísmo religioso universal o panteísta representado por los antiguos, especialmente (...) por el estoicismo romano. ${ }^{22}$

Reaparecerá, también, en la ilustración leibniziana; y con ello, el motivo fundamental de la filosofía griega quedará como uno de los problemas más importantes de la historia espiritual de los siglos siguientes. Con la entrada de la metafísica griega en la conceptualización teológica, territorio de prestigio y poder, irrumpe en la fe de la sociedad occidental. Uno de los mayores dramas de Occidente en la vida religiosa ha sido la persecución de cualquier atisbo de este panteísmo helenista, cuya formulación moderna escribe Spinoza y abandera Lessing. La sospecha de ateísmo con la que los eclesiasticismos de soteriología demoniaca y dramática cubren cualquier intento de pensar la unidad entre lo divino y lo humano es una de las mayores lacras de la vida espiritual occidental. Asustados ante la atenuación de la responsabilidad individual que este panteísmo podría conllevar, en vez de proceder con carácter liberador, la dogmática quiso que el individuo permaneciera individual para que pudiera responder por el pecado, y no para que su libertad individual diera origen a formas de autonomía y autosuficiencia. La concepción del hombre que piensa la ortodoxia, hombre muy alejado de Dios (por la creación) y muy debilitado (por el pecado), cristaliza en un ser humano asustado, penosamente beato, manejado a su antojo por las clases altas de la jerarquía eclesiástica.

La metafísica panteísta de origen helenista entró, como digo, en el debate intelectual de los primeros concilios cristianos. Sin embargo, el verdadero debate se jugó bajo la polémica cristológica, concretamente sobre la doble naturaleza de Cristo como Dios-hombre La parte más ortodoxa no aceptó ninguna tendencia a la continuidad entre Dios y la naturaleza que se alejara de la dualidad Creador / creación. Incluso con las posibilidades intelectuales que abría la concepción de Cristo como divino/humano como metáfora del hombre en general. Sin embargo, los filósofos griegos que presenciaron este tipo de disputas no se llevaron a engaño sobre lo que realmente se estaba jugando en la, aparentemente, inocente disputa cristológica. Lessing se hace eco de este tipo de actitudes en su texto El filósofo en el concilio $^{23}$. La conceptualización de la muerte toma tintes cada vez más plásticos, gracias a categorías prestadas por la ciencia jurídica romana; pues ahora el que moría en la cruz era Dios-hijo, deudor ante Dios-padre y por muerte en la cruz. Así, la dog-

\footnotetext{
22 Dilthey (1947), p. 91.

${ }^{23}$ Lessing (1990), pp. 608-610.
} 
mática que quería evita cualquier signo panteísta se aferraba a la idea de pecado como discontinuidad y ruptura en la historia universal y humana. Dice Lessing:

En nombre de Jesu Christi, la Palabra de Dios, que estuvo siempre con el Padre, jescucha, oh filósofo, la doctrina de la Verdad! No hay más que un Dios, que creó cielo y tierra y cuanto hay en ellos, que formó del polvo al hombre y que lo mantiene todo mediante su Palabra y su Espíritu Santo. Esa palabra, filósofo, es el hijo de Dios. ${ }^{24}$

Para Lessing, estas palabras 25 expresan el arquetipo de cristiano simple y sólido, que recita su regula fidei; en este caso, la fórmula trinitaria y "algo más". Este "algo más" expresa todos los intentos por reducir al hombre, mediante el pecado original, a polvo en las manos de dios. Reducción dualista que evita la autosuficiencia en el pensar que los vientos panteístas de la metafísica griega ponía en juego. Pues, como Lessing sabe, un ser que se cree responsable (por el pecado) y temeroso (ante Dios) es un ser fácil de convencer y más fácil de manejar a placer.

\section{Sobre la muerte en Lessing}

Lessing escribe, con sólo 21 años, su primer trabajo teológico: "Pensamiento sobre los de Herrnhuter"'26, siguiendo a Leibniz y a Shaftesbury, reconoce el intento de pensar las cosas teniendo en cuenta su naturaleza y su historia, una vida y unas leyes que le son inherentes al objeto del pensamiento. En este caso, el joven Lessing intentará pensar sobre una filosofía de la historia religiosa. El método lessingniano quiere partir del mismo comienzo del filosofar y de la revelación:

Va a parecer que me remonto mucho. Pero cuando menos se piense, me habré metido ya en harina. 27

Ya en estos primeros compases del pensar teológico de Lessing se ponen las bases de lo que será constante en su pensamiento. El artículo en cuestión presenta una nueva filosofía relacionada con el vivir y el morir. La culminación, en una fantasía o parábola que presenta esta nueva manera de actuar 28 , viene precedida por un anhelo filosófico. Que el tiempo traiga necesariamente a un nuevo filósofo que

\footnotetext{
24 Ibídem, p. 609.

25 Lessing estaba pensando en Pafnucio cuando escribió estas líneas. Pafnucio fue un sencillo confesor que fue sometido a martirio y que gozaba del favor del emperador; se cuenta que le habían arrancado un ojo y el emperador le besaba la cuenca vacía. Asistió al concilio de Nicea (año 325 d.C).

26 Lessing (1990), pp. 163-178.

27 Ibídem., p. 164.

28 "El hombre fue creado para la acción y no para elucubrar". Lessing (1990) p. 164.
} 
enseñe una manera diferente de vivir, que lo haga con humor y que nos enseñe a vivir en armonía con la naturaleza:

Imaginemos que apareciera en nuestros tiempos un hombre que, desde la altura de sus sentimientos, pudiera lanzar una mirada despectiva a las actividades más importantes de nuestros eruditos; que supiera descubrir con socrática fuerza los aspectos ridículos de nuestros loados filósofos y osara decir en confiado tono: Vuestra ciencia es aún la infancia de la Sabiduría, pasatiempo de prudentes, consuelo de orgullosa ceguera. ${ }^{29}$

El enlace genial entre la virtud y la generosidad, o el apoyo en la natural sensación de belleza y de bien ${ }^{30}$, independiente de los premios y castigos ultraterrenos del cristianismo, son las líneas hacia las que apunta este esbozo antropológico de Lessing. Con estos elementos se pretende construir una nueva manera de vivir. Y con ello, una nueva forma de morir. Pues ambas formas, saber vivir y saber morir, no pueden darse de forma separada. Por eso el texto nos pide al final un nuevo filósofo que:

... nos enseñará finalmente a caminar mirando a la muerte de frente, impasiblemente, y a demostrar, saliendo voluntariamente de este escenario, que se está poseído de la convicción de que no nos mandaría la Sabiduría quitarnos la máscara si no hubiéramos ya acabado nuestro papel. 31

El nuevo concepto de la muerte que pide Lessing se aleja eminentemente del pensamiento estoico, se aleja a su vez del pensamiento escatológico del cristianismo en la resurrección; se aleja, en fin, de la Biblia donde los patriarcas pueden acabar sus días tranquilos y seguros de haber vivido una buena vida:

Génesis 15, 15: "Tú, en tanto, irás en paz con tus padres, serás sepultado en buena ancianidad".

Génesis 47, 30: "Cuando yo me acueste con mis padres, me llevarás de Egipto y me sepultarás junto a ellos".

La muerte lessingniana se expresa como una acción que continúa la vida y que está dirigida por la Sabiduría divina; acción basada en la creencia de que todos pueden alcanzarla. En este pensamiento, basado en el antiguo teísmo que entendía el mundo como teatro y la vida como el papel que representamos, Lessing quiere ale-

\footnotetext{
29 Lessing (1990) p. 168.

${ }^{30}$ La circulación de las obras de Shaftesbury en el primer tercio de siglo en Alemania favorecieron la puesta en escena de estos elementos, constantes también en Lessing: humor, naturaleza inmanente, desinterés de la virtud...

31 Lessing (1990), p. 168.
} 
jarse de cualquier carácter depresivo de la idea de muerte, latente en el dualismo cristiano entre vida / otra vida; o en el indiferentismo estoico de llegar a morir. La Sabiduría nos impulsa siempre hacia cotas más alta de dicha y de conocimiento.

Los tres temas recogidos en el artículo pueden delinearse como:

1. La superación del miedo a una cierta muerte

2. la libertad para seguir el mandato de la Sabiduría o la Providencia

3. la concepción de esta vida como un papel a desempeñar

Se trata de tres elementos que ya Petrarca había acuñado (1304-1374) y que comenzaban en los siglos XVII y XVIII a tomar forma filosófica bajo el pensamiento de Spinoza, Leibniz, Shaftesbury y de Lessing. Éste desea una nueva interpretación de la muerte, alejada ya de la infancia de la Humanidad, donde pueda, en vida, quitarse la máscara por indicación de la Sabiduría y salir voluntariamente del escenario. ${ }^{32}$ La formulación sistemática de esta nueva forma de morir queda cristalizada en el escrito Educación del género humano, donde vincula el destino individual con el destino común de la humanidad entera, en una relación de co-pertenencia e indisociabilidad. En la Historia Universal se recurre a un concepto de vida cuya felicidad está unida a una acción que conduce a diversos estados de felicidad común; es decir, a una antropología no escatológica, alejada de conceptos como el de descanso eterno, juicio, gloria o infierno. Todos estos conceptos, con los que Occidente ha crecido, han dado metafísicamente todo lo que podían dar de sí. La muerte vinculada al juicio final corresponde a un estado infantil de la humanidad. Gracias a una concepción y a una fe fuerte para con el concepto de vida, la escatología perdería su poder como vía única de pensamiento sobre la muerte. Aunque consciente de que el trabajo filosófico, artístico y religioso que conlleva pasar de una cosmovisión en torno a la muerte a otra diferente es enorme, no obstante también sabe que a veces las grandes transiciones surgen de hundimientos instantáneos, cuando la experiencia de las generaciones no se sostiene más que por etéreos cimientos, no ya en conocimientos fundados y fe inquebrantable, desde el más grande imperio a la más antigua religión deben caer por su propio peso. La experiencia interna de estas generaciones es el motor impulsor, de origen divino. Cualquier religión del Espíritu sabe esto, igual que la naturaleza, que es "Espíritu naturalizado" (Shaftesbury), sabe del poder de esta fuerza que es la experiencia. Y la experiencia interna a la que Lessing se remonta cristaliza en el cruce entre el helenismo y el cristianismo. Pasando por la teoría de las mónadas de Leibniz.

\footnotetext{
32 La tradición nos ha dejado como anécdota que Lessing, poco antes de entrar en coma, levantándose gracias al apoyo de dos amigos, pudo exclamar: Diese Szene ist aus! (Esta escena se acabó); así que esta visión de la vida como un papel y el mundo como teatro le acompañó hasta el final. También en la última carta que escribió a Mendelssohn (19 de Diciembre de 1780) le dice ;Ay, amigo, se acabó esta escena!; en Lessing (1990), p. 34.
} 


\section{Principio de continuidad: de Leibniz a Lessing}

Lessing quiere sustituir la dualidad del mundo cristiano por la idea de un desarrollo constante, que será la cumbre de su pensamiento sobre religión. Para ello procede atacando el mismo fundamento de la religión revelada, comparándola con las supersticiones tradicionales en numerosas ocasiones. ${ }^{33}$ La comparación siempre surge en detrimento del cristianismo. Las formas supersticiosas de ganarse el porvenir se equiparan a las del cristianismo; dice Lessing:

(las razones) contra la astrología son las razones contra la religión revelada. Aunque fuera verdad que hubiera un arte de conocer el futuro, deberíamos preferir no aprenderla. Aunque fuera verdad que hay una religión que nos informa de una manera completamente indudable sobre aquella vida, deberíamos preferir no prestarle atención a esa religión. ${ }^{34}$

La crítica viene determinada por la seguridad desde fuera con la que se cubre el cristianismo (y las supersticiones). Este carácter externo de la seguridad distrae al hombre, más que ayudarle. Le pone demasiadas trampas para evitar el correcto avance del interior espiritual del ser humano. Lessing afirma, además, que el objetivo de la religión revelada no es ofrecernos la seguridad de un futuro transmundano. Al ponerse a ese nivel se asemeja más a prácticas de carácter astrológico. La religión, la verdadera religión del Espíritu, dirá Lessing, tiene como objetivo alcanzar, durante la extensión temporal de la vida humana (es decir, en el más acá) la perfección moral del hombre y de toda la humanidad.

La Era del Espíritu es hacia donde se debe dirigir la humanidad, vehiculizada por una mejor comprensión de la muerte, de la inmortalidad y de su relación con esta vida. Aquí Lessing es tajante: eliminación de la dualidad y cambio por el progreso y desarrollo constante, Leibniz mediante. Originalmente, la idea de un desarrollo constante se presentaba bajo la idea de continuidad del esfuerzo por la virtud mayor (perfección). Esta teoría apreciaba la continuidad o participación del alma mortal gracias a la intuición que el alma alcanzaba de lo inmutable e inmortal. Ahora, para Lessing, el nuevo argumento se basa en la infinitud de graduaciones del ser, desde la nada hasta el todo, en continuidad profunda. La continuidad es de grado moral, pero estrictamente en las antípodas de la antigua moral de premios y castigos. Es incluso capaz de olvidarse de infiernos y castigos eternos. Pues el dolor intensivo de tormentos eternos no es nada comparado con la alegría o dicha en el continuo perfeccionamiento moral.

\footnotetext{
33 Sobre todo en Donde la religión revelada prueba demasiado, es donde menos prueba, en Lessing (1990), pp.488-489; y en ¿Pope, un metafísico?, en Ibíd., pp. 277-311.

34 Lessing (1990), p. 489.
} 
Lessing señala la doble indisposición del alma:

1. A la inmovilidad (contradice su esencia)

2. Al continuo retroceso (contradice su naturaleza metafísica)

Una vez que el alma se "da cuenta" de que ha avanzado, aunque sea mínimamente hacia la perfección moral, se olvida del infierno. Dice Lessing:

(...) seguro que llegará el tiempo del cumplimiento cuando el hombre, a medida que su inteligencia se vaya convenciendo de que el futuro será mejor cada vez, no tenga ya necesidad de recabar de ese futuro motivos para sus acciones; el tiempo en que el hombre hará el bien por el bien y no porque se establezcan premios arbitrarios con el fin, propiamente, de fijar y robustecer su voluble mirada para que sepa ver los premios interiores del bien, que son mejores. ${ }^{35}$

Resulta curiosa la contraposición entre la idea de plantear este encaminarse hacia un futuro mejor y la explicación de carácter científico (psicológico) acerca de tal hipótesis. Pues si bien es claro los motivos por los que la razón postula la idea de continuidad (incomodidad interna a permanecer en un estado de imperfección que sea definitivo, la injusticia que traen consigo las imperfecciones morales, etc.) Lessing se muestra críptico a la hora de expresar el cómo se avanzará hacia mejor con la idea de continuidad. Según Dilthey, la especulación que lleva a cabo Lessing es del tipo "quimera metafísico-religiosa", quimérica precisamente por los anexos de metempsicosis y correlativa preexistencia. Lessing, consciente de que el nuevo estado sólo puede ser apuntado como horizonte de posibilidad, velado, sólo mostrado, utiliza en buena parte de las proposiciones finales de La Educación del género humano el carácter interrogativo: “¿Y si...?”; de esta forma, señala la posibilidad de la metempsicosis:

¿Por qué no ha de presentarse en este mundo cada individuo más de una vez?36

Bajo los cimientos de estos pensamientos de Lessing puede el arqueólogo hábil hallar restos que pertenecen a Leibniz. Pues la metafísica leibniziana, con el principio de continuidad y la idea de representación del alma en la otra vida, empujan a Lessing a pensar el camino del alma como dirigido hacia el continuo perfeccionamiento, siendo este camino inagotable y no teniendo otra meta que el perfeccionamiento en sí mismo. Pues si bien la filosofía es incapaz de decirnos cuál será el estado de las almas en una pretendida vida futura, la razón nos dice que el alma no estará ni estéril ni inmóvil. Así pensaba Leibniz y así lo entendió Lessing. El alma humana no puede alejarse de su esencia, que es la continua actividad, ni su natura-

35 En La Educación del género humano, Lessing (1990), § 85, p. 645.

36 Ibídem., § 94, p. 646 
leza metafísica, que es la de continuo progreso. La felicidad del hombre no puede reposar nunca en un estado de dicha completa, donde todo es reposo y calma. Nuestro espíritu ha de continuar el camino hacia la continua perfección y constante progreso con nuevas formas de placer y nuevas cotas de perfección.

Del mismo modo que Schleiermacher, Lessing afirma que todos los individuos están destinados al continuo esfuerzo de sus facultades. Pues cada alma participa de todo lo que consigue la Humanidad, y viceversa. Se crea así una suerte de red donde cada esfuerzo individual repercute en el progreso constante de todos los hombres. Por eso, afirma Lessing, no tenemos que desesperarnos porque nuestras fuerzas no alcancen a realizar todo lo que queramos: podemos aparecer en este universo, ya sea en forma humana, ya sea mediante otra forma, las veces que haga falta:

La gran rueda lenta que va acercando al género humano a su perfección sólo se pondría en movimiento mediante ruedecitas más rápidas, cada una de las cuales aportaría su particularidad. 37

La teoría de las mónadas de Leibniz surge como un intento de unir los conceptos de la naturaleza con aquellos otros que hacen comprensible el mundo espiritual. La teoría de las monadas, de carácter metafísico, presenta a éstas como comunidades vivas que no pueden ser desarticuladas. Al no poder disociarse, carecen de extensión real en el espacio (no son espaciales), por lo que se ha de acudir al reino de lo espiritual para poder pensar sobre ellas. Se constituyen así como fundamento de lo material y del orden interno de la materia, a la vez que en su propia evolución contribuyen a los más elevados aspectos de lo espiritual.

Esta doble conceptualización de las mónadas representa una nueva salida para el denominado problema psicofísico (cómo se unen y que relación guardan entre sí la res cogitans y la res extensa); para Leibniz, con la teoría de las mónadas, es la psicología el campo fundamental dentro de la inteligencia del mundo. Por un lado, cada realidad tiene que ser pensada por analogía con el reino espiritual. Así, podemos definir el mundo físico como fenómeno del mundo espiritual. El hombre, en este mosaico, puede definirse como una reunión de mónadas, dentro de la cual rige aquella mónada que es el sustento de todas las manifestaciones en el mundo espiritual.

Dentro de la teoría metafísica de Leibniz, aparece el principio de continuidad, que tanto inspiró a Lessing. Dice Dilthey al respecto:

El mundo orgánico requiere una razón explicativa que nos haga comprender la forma y la conexión del todo y la unidad vital espiritual exige, además, una razón explicativa de la espontaneidad unitaria de sus manifestaciones. De esta dirección universal, finalmente, surge el empeño de concebir el universo como una conexión interna cuyos miembros se trasfunden unos en otros en continuidad. 38

37 Ibídem., § 92, p. 646.

38 Dilthey (1978), p. 462. 
El principio de la forma es el núcleo fuerte desde el que Leibniz coloca la razón explicativa de las propiedades de unidad del mundo físico y del mundo espiritual. Mediante argumentaciones de carácter matemático, la doctrina se expresa no obstante como doctrina metafísica. De tal suerte que, para Leibniz (y para Lessing), el principio de continuidad es inherente a las partes últimas de la realidad, lo que hace que dentro de cada una de ellas surja una capacidad de desarrollo infinito. El enlace entre estas partes no es de carácter físico, sino que existe un ordenamiento primigenio por el cuál tienden a la armonía de manera natural. Se extiende por toda la realidad una especie de gradación, que va desde lo inconsciente hasta la claridad de la conciencia, de todos los elementos de la realidad de una forma armónica, por medio de la evolución y de la continuidad. He querido acotar la teoría de Leibniz desde la perspectiva de Lessing para poder llegar a donde quería llegar: la antropología de Lessing.

\section{Conclusiones: hacia una nueva antropología}

Y es que si Lessing habla tanto de la muerte es porque realmente desea llegar a una nueva teoría sobre la vida del ser humano. Esta nueva idea del hombre nace en Lessing del juego constante entre las tradiciones judía y griega, donde Lessing aspira a conseguir una concepción tal que le permita al ser humano llegar hasta donde no ha llegado nunca, inclusive en el campo político.

La teoría de carácter leibniziano y lessingniano sobre la "transmigración de las almas" repercute en una concepción de la vida alejada de la escatología judía y cristiana. Por mucho que sorprenda a propios o extraños, Nietzsche retoma los presupuestos de Lessing a finales del siglo XIX. Desde entonces, ésta concepción no puede entenderse burdamente como transmigración de las almas, simplemente. Es precisamente en la antropología (en la concepción de la muerte) donde esta otra Ilustración toma las riendas para el replanteamiento moral. Pues si la concepción de la transmigración de las almas es, a ojos vista, una extravagancia del pensamiento, ésta surge de una intuición plenamente humana. Dicha intuición tiene que ver con pensar la inteligencia humana como una categoría que no se deja encerrar en el campo sensorial. Es en este campo donde opera la figura del esqueleto, descarnado, que le aleja de un lugar y de un tiempo (que le era concebido por la carne). Sin embargo, hay algo más que reverbera en las profundidades: la fuerza esencial que late en el fondo de la mónada.

En la segunda mitad del siglo XVIII, se da un giro hacia presupuestos de la Antigüedad, especialmente en lo que concierne a la escatología. Comienza a aflorar un descreimiento hacia el temor por el juicio final o el miedo al infierno. Los hombres vuelven a sentir curiosidad por la relación que los antiguos mantenían con los muertos. Durante la Edad Media, los familiares se deshacían del cadáver de sus 
seres queridos dándoselo a la Iglesia. Ahora vuelven a preocuparse por sus difuntos. Vuelve a surgir la motivación por escribir epitafios de forma más personalizada, de venerar la tumba, de cuidarla e ir a visitarla. Comienza, en fin, un acercamiento entre el más acá y el más allá que ya se daba en la Antigüedad.

Es "la muerte de la muerte", dice Agustín Andreu ${ }^{39}$. Con la concepción que une en Lessing la transformación, el continuo perfeccionamiento y la metempsicosis, el hombre comienza a vivir una nueva vida. Lejos de apremios, de dudosas intenciones morales basadas en el miedo al castigo divino, el hombre puede darse a la perfección de su ser, esperando a la muerte sin miedo ni rencor. Es el tercer gran paso de la humanidad: la era del Espíritu. Alejados de la era de Dios-padre y de la venida de Jesús (Dios-hijo), el hombre es ahora uno con toda la humanidad. El paso a la era del Espíritu tiene que venir, según Lessing, guiado por la razón, pues se trata de un aumento de la moralidad individual y colectiva. Mediante las continuas revelaciones en el decurso de la historia, la Sabiduría ha ido produciendo una educación que ha buscado el crecimiento de la vida esencialmente humana. Y lo más humano que hay en la vida de los hombres es la vida ética: los motivos, ideales y motivaciones por las que el hombre rige su acción, sus deseos, preferencias y pensamientos.

Cuando Lessing escribió Sobre la posibilidad de que un día tenga el hombre más de cinco sentidos 40 en el año 1780, estaba intentando argumentar a través de la biología las posibilidades de su teoría sobre la muerte y el perfeccionamiento continuo. El sujeto al que apela Lessing es un sujeto espiritual, que ha sido capaz de ir avanzando éticamente y que está preparado para la era del Espíritu. La ortodoxia de la iglesia ya había comenzado a poner el grito en el cielo: sin premios ni castigos, sin juicio divino ni salvación / condenación eterna, no se puede tener controlado al hombre culpable, y por tanto, no es posible ni la religión, ni la sociedad, ni el estado ni la propiedad privada. Pero obviamente Lessing no se detuvo ante dichas advertencias.

Pues lo importante para Lessing era conocer; y conocer hasta el final significa tirar del hilo de la razón, independientemente de qué dogmas o creencias tengas que derribar en el camino. Si no aguantan el envite de la razón, no son dignas de permanecer por más tiempo en pie. La humanidad a lo largo de la historia ya ha agotado todos los preceptos que desde fuera se le han impuesto. En el ámbito político eso ha quedado traducido en una didáctica que se pasa de paternalista, y que ha quedado alejada de la consecución de un perfeccionamiento continuo. Las autoridades eclesiásticas han ido jalonando sus templos de oro a base de miedo, avaricia y remordimientos. Las autoridades políticas han reducido su lucha por un bien común mayor a meras disputas dialécticas carcomidas por la envidia y el ansia de riquezas.

Hemos visto como la Iglesia-Institución ha bebido de las fuentes de Pablo de Tarso, y al embriagarse de pecado original y salvación, han estipulado en Cristo la

39 Lessing (1990), p. 125.

40 En Lessing (1990), pp. 420-425. 
figura de un segundo Adán redentor por contraposición al primer Adán-culpable. Hemos visto, además, como existe una tradición que busca en el helenismo rasgos de carácter panteísta como contraposición a la regla de regalos y castigos en el más allá. Como desde Bruno, Spinoza, Leibniz y Lessing, se ha intentado pensar la relación entre la vida y la muerte desde otra perspectiva. Ahora viene lo importante: con la teoría de la transmigración de las almas, Lessing niega la muerte. Al negarla, es imposible que se convierta en instrumento para la salvación eterna.

¿Cómo negar la muerte? Igual que Juan, que no se podía morir 41 , como decían sus discípulos, Lessing afirma poco antes de su entrada en coma: Se acabó esta escena. No es que se haya acabado la obra, ni que sea la última escena: ha concluido esta escena (la vida terrenal de aquí y ahora) para dar paso a la siguiente (que se manifestará bajo otra forma pero que repercutirá igual en el perfeccionamiento de toda la humanidad). La consecuencia es clara: esta vida no es el único momento de merecer que tenemos antes de enfrentarnos al juicio final. Del esquema dualista vida / otra vida surge el esquema cristológico entre humillación/exaltación, ya presente en:

Filipenses 2, 5-7: "Tened entre vosotros los mismos sentimientos que Cristo: el cuál, siendo de condición divina, no codició el ser igual a Dios sino que se despojo de sí mismo tomando condición de esclavo".

La antropología aquí subyacente es la conocida por todo el mundo. Cristo-Dios se reduce a hombre por mandato de Dios-padre, y muere en la cruz, por lo que Dios le glorifica y le exalta. Este es el esquema que va desde Agustín de Hipona hasta Lutero. Y sin embargo, Leibniz actualiza a Spinoza, mostrando una concepción que pervivirá en Goethe, Herder y Lessing:

Leibniz, que había pugnado por penetrar las misteriosas profundidades del cristianismo, desaloja la divinidad de la ira y el perdón, enseñada en el dogma de la redención y la justificación, introduciendo una visión (espinosiana de este mundo) como la más perfecta realización de todos los grados de la fuerza, la vida y la felicidad. ${ }^{42}$

Lessing es optimista; es optimista por el "Uno y Todo" de Spinoza que se va desplegando según una ley de carácter leibniziano de gradualidad imperceptible. Poco a poco, paso a paso, el mundo va mejorando. Casi de manera imperceptible, afirma Lessing, pero avanza. Es un proceso que puede resultar muy duro para aquellas mentes preclaras que se adelantan a su tiempo. Es además muy infantil creer que las dificultades teóricas que surgen en una época deben de ser resueltas en esa misma época. La perspectiva histórica siempre acomete los problemas con una dis-

${ }^{41} \mathrm{Al}$ respecto consultar El testamento de Juan, en Ibíd., pp. 490-497.

42 Dilthey (1978), pp. 29-30. 
tancia suficiente como para hacerse cargo de ellos. En La Educación del género humano Lessing se hace cargo de este perfeccionamiento apenas perceptible como si de un valor se tratase. Antropología monádica e irreductible unidad de toda individualidad con el Todo: estos son realmente los vectores fundamentales en la antropología de Lessing. Cada mónada irá poco a poco, en un proceso constante, tendiendo a la perfección. Es un proceso largo, pero no por ello fatigoso, pues para el individuo se ha abierto el horizonte de la eternidad. Eternidad no basada en premios ni castigos ni juicios divinos; es un proceso que viene empujado desde dentro. Igual que la Historia, que es impulsada desde dentro a paso lento, la mónada va paso a paso buscando su camino. Siempre a mejor.

\section{Referencias bibliográficas}

Bruno, G. (1989): Expulsión de la bestia triunfante. Madrid. Alianza Editorial.

DiltheY, W. (1978): Hombre y mundo en los siglos XVI y XVII. México. Fondo de Cultura Económica

Lessing, G.E. (1985): Natán el Sabio. Madrid. Selecciones Austral-Espasa Calpé.

LESsING, G.E. (1990): Escritos filosóficos y teológicos. Barcelona. Editorial Anthropos.

LeSsing, G.E. (1992): La Ilustración y la muerte: dos tratados. Madrid. Editorial Debate.

Lessing, G.E. (1992): Cómo los antiguos se imaginaban la muerte. Madrid. Editorial Debate.

Lessing, G.E. (1992): Sobre los elpísticos. Madrid. Editorial Debate.

Puech, H.Ch. (1957): Maniqueísmo: el fundador, la doctrina. Madrid. Instituto de Estudios Políticos.

Villacañas, J.L. (1993): Tragedia y teodicea de la historia. El destino de los ideales en Lessing y Schiller. Madrid. La balsa de la medusa, Visor.

VILLACAÑAS, J.L. (1994): La quiebra de la razón ilustrada: idealismo y romanticismo. Madrid. Ediciones Pedagógicas.

V.V.A.A. (1998): Biblia De Jerusalén. Bilbao. Editorial Desclée de Brouwer.

Iván Fernández Frías

Facultad de Filosofía

Universidad Complutense de Madrid

ivanfernandez@estumail.ucm.es 